https://www.amerabra.org; https://fspu.uitm.edu.my/cebs; https://www.emasemasresources.com/

$5^{\text {th }}$ ABRA International Conference on Quality of Life

Holiday Villa Langkawi, Langkawi Island, Malaysia, 15-16 Dec 2021

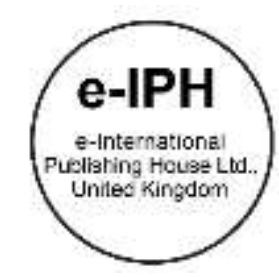

\title{
A Qualitative Study of Psychological Challenges towards Movement Control Order among Stranded University Students
}

\author{
Suzana Yusof ${ }^{1}$, Nurul Amirah Mohd Bakri' ${ }^{1}$ Umi Syafiqah Che Wahab ${ }^{1}$, Angga Wilandika ${ }^{2}$ \\ ${ }^{1}$ Centre for Nursing Studies, Faculty of Health Sciences, Universiti Teknologi MARA Puncak Alam Campus, Selangor, Malaysia \\ ${ }^{2}$ Medical-Surgical Nursing Department, Faculty of Health Sciences, Universitas 'Aisyiyah Bandung, Indonesia
}

suzanay@uitm.edu.my, amiirah1998@gmail.com, umisyaaafiqah@gmail.com, wiland.angga@unisa-bandung.ac.id Tel: +60123659680

\begin{abstract}
The stranded students were vulnerable to developing psychological problems as they were separated from their families and lived alone. This research aimed to explore the psychological challenges experienced by stranded university students and support that assists those dealing with the challenges during MCO. This qualitative phenomenology study was conducted using in-depth and focus group interviews via online meetings. A total of 12 stranded university students were selected. Three themes emerged from the analyses: psychological challenges, hoping for better management in disaster conditions, and financial and emotional supports are survival during stranded in MCO situations.
\end{abstract}

Keywords: Movement Control Order (MCO); psychological challenges; stranded; university students

eISSN: 2398-4287@ 2021. The Authors. Published for AMER ABRA cE-Bs by e-International Publishing House, Ltd., UK. This is an open access article under the CC BYNCND license (http://creativecommons.org/licenses/by-nc-nd/4.0/). Peer-review under responsibility of AMER (Association of Malaysian Environment-Behaviour Researchers), ABRA (Association of Behavioural Researchers on Asians/Africans/Arabians) and cE-Bs (Centre for Environment-Behaviour Studies), Faculty of Architecture, Planning \& Surveying, Universiti Teknologi MARA, Malaysia. DOI: https://doi.org/10.21834/ebpj.v6i18.3078

\subsection{Introduction}

The severe acute respiratory syndrome coronavirus-2 (SARS-CoV-2) is a newly discovered coronavirus that is highly infectious and contagious affects the human respiratory system. COVID-19 epidemics emerged in Wuhan, China, last December, and since then, it has developed into a global public health concern for China and countries worldwide (Phelan et al., 2020). As a measure, Malaysian authorities have enforced a nationwide pandemic action plan known as Movement Control Order (MCO) since March 2020 (Shah et al., 2020).

All public gatherings were prohibited after the government implemented the MCO, which resulted in all universities in Malaysia being temporarily closed to prevent the spread of the virus. Following the YAB Prime Minister's declaration of the MCO, the Ministry of Higher Education (MOHE) Malaysian had ordered the students not to leave their current residence within 24 hours of the announcement. Hence, many students stay at university hostels, and their rental accommodation is stranded (The Star, March 19, 2020). They started to feel worried and anxious for a more extended period (Zakaria et al., 2021). Indeed, it is also well recognized that prolonged isolation and separation from family harm students' mental health (Omar et al., 2021).

The government provided RM12.2 million in food aid to 74,530 stranded students (New Strait Times, March 23, 2020). In times of turbulence, access to psychological support, communication, and internet facilities are among the most basic requirements. Concurrently establishing psychological and mental resources for crisis intervention can reduce psychological distress and improve mental resilience (Binti et al., 2021). There is a need to explore the stranded college students' experiences in this challenging situation and how it affects their quality of life.

eISSN: 2398-4287@ 2021. The Authors. Published for AMER ABRA cE-Bs by e-International Publishing House, Ltd., UK. This is an open access article under the CC BYNCND license (http://creativecommons.org/licenses/by-nc-nd/4.0/). Peer-review under responsibility of AMER (Association of Malaysian Environment-Behaviour Researchers), ABRA (Association of Behavioural Researchers on Asians/Africans/Arabians) and CE-Bs (Centre for Environment-Behaviour Studies), Faculty of Architecture, Planning \& Surveying, Universiti Teknologi MARA, Malaysia.

DOI: https://doi.org/10.21834/ebpj.v6i18.3078 


\subsection{Literature Review}

According to the American College of Health Association and the World Health Organization (WHO), increased psychological stress and psychological issues are frequent among college students. As these young adults are primarily in their studying period, a pandemic outbreak may impact their lives. A cross-sectional study discovered that around 683 students reported that COVID-19 significantly impacted their studies (Dodd et al., 2021). Compared to other occupational statuses such as work or retirement, student status was revealed to be a significant risk group for acquiring more significant psychological problems (González et al., 2020).

Many recent studies found the psychological impact of quarantine or lockdown on students. Such as there is a study conducted by Cao et al. (2020) on Changzhi medical college students in China using a 7-item Generalized Anxiety Disorder Scale (GAD-7) to examine the psychological effect of the COVID-19 pandemic. There were $0.9 \%$ of students with extreme anxiety, $2.7 \%$ moderate pressure, and $21.3 \%$ mild anxiety among the 7143 students surveyed. In addition, previous research has shown that public health crises may have psychological consequences for college students, such as anxiety, fear, and concern (Cao et al., 2020). Similarly, a recent study by Camacho-Zuñiga et al. (2021) found that the most mentioned feelings during lockdown were anxiety, tension, overwhelm, tiredness, and depression. This result is consistent with findings from other studies conducted in university populations in Spain, where half of the respondents reported moderate to severe psychological impact from the outbreak (Odriozola-González et al., 2020), as well as in other countries worldwide (Cao et al., 2020; Wang et al., 2020).

Hakami et al. (2020) examined that the students who lived alone were more likely to experience psychological challenges during the COVID-19 pandemic. In Malaysia, Sundarasen et al. (2020) reported that 20.4 \%, 6.6 \%, and $2.8 \%$ of students, respectively, experienced minimal to moderate, marked to severe, and most severe anxiety levels among Malaysian university students during the COVID-19 outbreak and MCO period in April and May 2020. A recent qualitative study explored the experience of five stranded college students during the COVID-19 outbreak and reported that the participants experienced mixed emotions of loneliness, regret, and frustration (Cahapay, 2020). Moreover, the severe threat to their safety and security during the pandemic may have made these students feel even more distant, posing challenges from several perspectives. (Zakaria et al., 2020).

Previous research has established that university's welfare, such as facilities, information updates, and food provided, was the most beneficial aids in influencing their emotions. They were satisfied with the facility's welfare that was provided to them (Khairul et al., 2021; Zakaria et al., 2021). Therefore, the university management should provide free food and necessities such as toothpaste, soap, and others for students as a practical attempt to maintain the well-being of their students and relieve parental concerns (Nor Hayati Endan, 2020). Monitoring long-term loneliness and responding quickly is critical in reducing students' anxiety helpful a feeling of community. University influencing role in helping students deal with their dissatisfaction, recommendations are counselling favored (Yang et al., 2020; Bao et al., 2020). Universities should implement digital psychological interventions, such as software applications, online programs for students, and other services, including messages, chat lines, blogs, and phone calls (Holmes et al., 2020). Other than that, Universities can also provide counselling support, either in person or online, to help students cope with their studies' emotional and mental implications.

\subsection{Methodology}

This study was carried out using a Phenomenology Qualitative Study Design, which allows for a deep understanding of a phenomenon by exploring it from those who have experienced it (Teherani et al., 2015). Phenomenological methods focus on the feelings and experiences of participants instead of individual characteristics. In this study, the researchers explored the psychological challenges experienced by stranded college students during Movement Control Order (MCO) in UiTM Puncak Alam Campus.

This study was conducted through in-depth interviews and focus group discussions via an online meeting platform among students at Dahlia and Casuarina College aged between 21 and 24 years old until saturation of data achieved (12 participants) It has previously been recommended that qualitative studies require a minimum sample size of at least 12 to reach data saturation (Fugard \& Potts, 2015).

A semi-structured interview question was used in this study for an interview guide. The session began with the researchers introducing themselves, explaining the objective of the interview briefly. Then the open-ended question was asked to initiate the conversation until data was saturated. Further exploration focused on the main topic, such as psychological challenges of stranded college students during the initial, adaptive, teaching-learning and sending-home student phase and support received while stranded in college.

The recorded interviews were transcribed verbatim manually using thematic analysis. The process involved repetitive reading and careful line-by-line analysis of the manuscripts. Each sentence was coded; then similar codes were grouped to be the emergent themes with similar messages. We continued the process until there was no newer themes discovered. Discussions were done between team members over any disagreement of the themes or content. The final read of articles was done to ensure that the main theme represented the participants' general information. The approval letter was granted on February 10, 2021 (REC/02/2021 (UG/MR/75).

\subsection{Findings}

A total of 12 stranded students consisting of eight females and four males from UiTM Puncak Alam were interviewed in this study. Participants aged between 21 to 24 years old during the interview session. Eight of the participants were from West Malaysia, while four of them were from East Malaysia. All participants are bachelor's degree students. They were stranded at the UiTM Puncak Alam college between March to May 2020. More specifically, half of them stay at Casuarina College while the other half stay at Dahlia College. Three themes emerge from the analyses; i) Psychological challenges, ii) Hoping for better management in disaster conditions and iii) Financial and emotional support are survival during stranded in MCO situations. 


\subsection{Theme 1: Psychological Challenges}

The analysis of the psychological challenges experienced by stranded college students during several phases of MCO, including the initial phase, adaptive phase, teaching-learning phase, and lastly, sending home students. This theme led to six sub-themes: a) stress, b) loneliness, c) Feeling of acceptance, d) bored, e) Online Distance Learning (ODL) obstacle, and f) exhaustion. The majority of the participants said that various contributing factors stressed them during the stranded period at college. They highlighted a few stressors, including being left by most of their friends, planned was cancelled, learned online, and was uncertain about their status. For example, a respondent whom her close friend had left said:

"I'm a bit stressed since everyone has returned to their home. Then, there were only a few students who did not return".

Many participants express their loneliness because of being stranded at college. Since there are only a few students remained, many have already returned home. A female student who was stranded alone at Dahlia College because all her close friends had returned to their home before total lockdown at UiTM said:

"All my close friends have already gone back home while I am still at college alone. So, I was lonely and must adapt to this situation alone."

During the adaptive phase, most participants highlight that they feel pretty happy and can adapt well to the current situation as time goes by. For example, in her second year of study, a participant said, at first, she was stressed, but after a few weeks stranded at college, she could adapt well.

"At first, I was stressed, but as time goes by, I can adapt and be happy because I not only the ones who are stranded here, but there are still some students."

Most participants mentioned boredom due to the lack of activities available to them when stranded at the campus. Furthermore, most of their friends had returned home, making them even more bored. For example, a female student who stays at Dahlia college said:

"At that time, I felt bored because there were no activities to do."

Most participants said they found it difficult to adjust to the new learning platforms during the ODL phase. They began to emphasize a few challenges they encountered while learning online, such as being easily distracted, having difficulty understanding, and completing group assignments. A participant who in her final year study said:

"When we sit in front of a laptop, it is easy to be distracted, so it's hard for us to focus on the online class."

The phase where they were sent home was a bit challenging to most stranded students because they were rushed and tired by mentioning they had a hard time facing the process of returning home that the university arranged. A Muslim's participant who was fasting at that time said that the process returns home take too long period that makes her need to break her fast with the non-conducive environment:

"During the day of returning students, the students must wait for the bus for a quite long time. We arrived at UiTM Shah Alam in the afternoon. We broke fast there with a lot of people and luggage. The next morning, we departed from there to Pahang".

\subsection{Theme 2: Hoping for better management in disaster condition}

From what researchers had found out from those students via interviewing them, most of them were hoping for better management by the university's authorities and strict rules when dealing with stranded university students in disaster conditions. Most participants expressed their disappointment and anger toward the management because they always give sudden and unclear information. As a result, it affected students, especially their psychology. For example, a participant expressed his frustration feeling during stranded at college:

"Other students can return to their home while I couldn't, so I was a bit disappointed, that is all psychologically."

Confining at the same place was an unpleasant experience for most people, including stranded students. Most participants complained that they felt confined and trapped at their colleges due to strict rules implemented by university management. They are not allowed to do some outdoor activities, including recreation activities. One of the participants revealed that:

"At least they should let us out for a walk around the college and jog. Like in the early MCO, they were angry at me when I was jogging at the college field even though I was alone at that time".

\subsection{Theme 3: Financial and emotional support are survival during stranded in MCO situation}

Being stranded at college was tough, especially for the students, because this situation was quite alien for them after being exposed to COVID-19. Thus, the support that they received during stranded helps them survive at college during this MCO. Several elements are discussed as a subtheme, including financial support and emotional support. Most stated that they received free meals, snacks, and personal needs while stranded at college. All the participants expressed their happiness and felt satisfied with the support received. A participant from East Malaysia said:

"We always had enough foods here; we are delighted and grateful".

Most participants mentioned that their lecturer was always responsive and never neglected them even though most lecturers stayed away and resided outside the campus. A Participant who stays at Casuarina College said:

"And then, there was also some support from the lecturer, and they gave snacks such as biscuits, Maggi, and personal necessities." 
Most of the participants said that while stranded at college, they received much emotional support, which helped them survive, especially family members and friends. Family plays an essential role in somebody's life, including emotional support, especially in this challenging time. Most of the participants had highlighted their parents and family as the most extensive dynamic support system when dealing with these challenges in an MCO situation. A participant from Pahang said:

"During that time, I received a lot of support from many parties such as moral support. for example, from family and friends".

The majority of participants also mention their peers who are always concerned about their condition and motivate them. For example, a female student who said her friends always cared about her condition:

"Apart from that, my friends are always concerned about me and ask about my condition. They cheer me on before I go back to our home.. So, we have received a lot of supports."

\subsection{Discussion}

The current study found that during MCO, stranded college students face psychological challenges. Stress, loneliness, boredom, acceptance, online learning obstacles, and exhaustion were the most reported psychological challenges among stranded college students. This finding is consistent with Fura et al. (2020), who concluded that most reported psychological challenges among students during confinement include fear, worries, lost confidence, anxiety, stress, lost interest, worthless, afraid, and tension. The majority of the participants experienced stress during all four phases of MCO.

During the initial phase, most students were unhappy and had been experiencing stress since the beginning of MCO because they could not return home. It is parallel to a previous study conducted at the University of Spain, which found a positive correlation between increased stress and event impact during the initial weeks of confinement (Odriozola-Gonzalez et al., 2020). Learning online and uncertainty about their status of returning home were highlighted as the sources of stress among the participants and the interview session.

One of the most significant points stated by the stranded students is that most of them felt lonely because of the pressure of being alone when staying at the campus without their friends and family. This result agrees with those obtained by Cahapay (2020), who found that stranded college students felt a mix of loneliness, remorse, and frustration during the COVID-19 pandemic. Following the present results, previous studies (Syabrina et al., 2021; Hakimi et al., 2020) have demonstrated that stranded students felt lonely while alone in hostels because they had no one to communicate with in person.

The current study indicated that stranded university students also face boredom and the stress and loneliness they face because university authorities prohibited all outdoor games or activities. Discontinuation of employment and activities and less contact with other people upset everyday lives and lead to boredom. Other than taking online classes, the most common activities stated by our participants were watching movies, eating, playing games, and sleeping. Interestingly, most participants believe that these activities can help them release and alleviate their sorrow while also filling their time. Similarly, the local qualitative study by Syabrina et al. (2021) discovered that stranded students would watch the movie to release stress and boredom. Learning' online is also found to be a significant challenge in the current study. The majority of students were preferred physical classes rather than online classes. A prior study (Chakraborty et al., 2020) also confirmed that learning face-to-face was better than ODL. Since being stranded at the campus, the majority of students have expressed their acceptance throughout the day.

In the second theme, the participants described their feeling and complained about the management in disaster conditions. This study found that the majority of the participant were upset with the current management, which is that the university management always gave sudden and last-minute decisions. Thus, they hoped that the institution should plan and organize properly not to provide the students with implications if this problem arises again. A study by Hasanagic (2020) also emphasized the importance of having a strategic plan to deal with and mitigate the effects of a catastrophe. Almost all of them already bought the bus or flight ticket after hearing about MCO enforcement in Malaysia. The participants from east Malaysia experienced a sense of stress when their flights to Sabah were canceled last minute. This demonstrates that it has an impact not just on emotions but also on finances. At first, the stranded students were allowed to go home, but it was only "Fake hope." They can only hope for good news because Eid Al-Fitr is approaching. To compensate for the situation, these students celebrate Raya together with friends and residence staff. At least, it could alleviate their sadness and frustration for not being together with their family members.

The majority of the participants expressed dissatisfaction with their colleges, claiming that they felt restricted and trapped. They thought the institution would let them participate in some outdoor activities. Similarly, stranded college students in the Philippines expressed a desire for some space after a pandemic hit their country (Cahapay, 2020). Their psychological and behavioral patterns may occur due to fewer physical activities, outside activities, and the opportunity to interact with friends and family (Moore et al., 2020). Thus, it is important to keep in contact with students all the time. Universities should implement systematic programs including life skills training and mindfulness therapy, that have been shown to alleviate anxiety (Sundarasen et al., 2020).

Since the first day of MCO implementation, these stranded students have received financial support from the college, lecturers, university authorizes, faculty members, and staff in the form of free meals, personal belongings, and donations. The government's and universities' coordinated actions and initiatives, such as giving food, may have considerably decreased the negative impact of a pandemic, loneliness, and ambiguous conditions on stranded mental health students. The majority of the participants mentioned their parents and relatives as the most importantly emotional support system. Similarly, the previous study found that high perceived emotional support from family and friends was significantly related to their emotions during COVID-19. This study found that high perceived emotional support from family and friends was greatly helping people feel sustained and share their feelings during COVID-19 (Zhang et al., 2020). 


\subsection{Conclusion \& Recommendations}

The most psychological challenges stated by the students are that most of them were stressed, lonely, bored, feeling of acceptance, ODL obstacles, and exhausted when staying at the campus. Furthermore, the students also struggled the most in following all the university authorities' rules and instructions while adapting to new things. Almost all participants were quite upset and disappointed with the current management utilized by university authorities. However, this study indicated that many parties supported students while stranded at residential colleges, especially the university itself. All of them were satisfied after receiving all that supports. Undeniable, emotional support from family and peers plays a vital role in ensuring these students' psychological well-being.

The government must act in the future to deal with stranded students to prevent them from developing psychological problems at that moment. The students should be given space for physical activities during $\mathrm{MCO}$, encourage them to voice out their feeling and the method of delivering ODL lessons should be varied, and their wish for improved management should be given in a clear and timely manner so that students may take early action in the future. The limitation of this study as it was conducted during MCO and the interview sessions cannot be conducted face to face. So, certain responses or facial expressions during the interview could not be obtained when there was internet interruption happened. For future study, it would be recommended to conduct face-to-face interviews in a bigger scale population.

\section{Acknowledgement}

We thank the participants who participated and spent their time in this study.

\section{Paper Contribution to Related Field of Study}

This study contributed to the body of knowledge that could be used to enhance the management of university students during a disaster such as COVID-19 in the future.

\section{References}

Bao, Y., Sun, Y., Meng, S., Shi, J., \& Lu, L. (2020). 2019-nCoV epidemic: address mental health care to empower society. In The Lancet (Vol. 395, Issue 10224, pp. e37-e38). Lancet Publishing Group. https://doi.org/10.1016/S0140-6736(20)30309-3

Binti, Abdullah, A., \& Haque, M. (2021). Initial 10 days into COVID-19 movement control order of Malaysia: How well did we fare? Advances in Human Biology, 11(1), 106. https://doi.org/10.4103/AlHB.AlHB_146_20

Cahapay, M. B. (2020). Stranded College Students amid Corona Virus Disease 2019 Pandemic: An Existential Phenomenology. Journal of Loss and Trauma, 25(6-7), 598-604. https://doi.org/10.1080/15325024.2020.1770955.

Camacho-Zuñiga, C., Pego, L., Escamilla, J., \& Hosseini, S. (2021). The impact of the COVID-19 pandemic on students' feelings at high school, undergraduate, and postgraduate levels. Heliyon, 7(3), e06465. https://doi.org/10.1016/j.heliyon.2021.e06465

Cao, W., Fang, Z., Hou, G., Han, M., Xu, X., Dong, J., \& Zheng, J. (2020). The psychological impact of the COVID- 19 epidemic on college students in China. Psychiatry Research, 287, 112934. doi:10.1016/j.psychres.2020.112934.

Chakraborty, P., Mittal, P., Gupta, M. S., Yadav, S., \& Arora, A. (2020). Opinion of students on online educationduring the COVID-19 pandemic. Human Behavior and Emerging Technologies https://doi.org/10.1002/hbe2.240

Fura, D. L., \& Desalegn Negash, S. (2020). A Study on the Living Experiences of People during the COVID-19 Pandemic: The Case of Wolisso Town Home-Stayed University Students. J Psychol Psychother, 10(5), 384. https://doi.org/10.35248/2161-0487.20.10.384

Fugard A. J. \& Potts, H. W. (2015). Supporting thinking on sample sizes for thematic analyses: a quantitative tool. Int J Soc Res Methodol. 18(6):669-84.

Hakami, Z., Khanagar, S. B., Vishwanathaiah, S., Hakami, A., Bokhari, A. M., Jabali, A. H., Alasmari, D., \& Aldrees, A. M. (2020). Psychological impact of the coronavirus disease 2019 (COVID-19) pandemic on dental students: A nationwide study. Journal of Dental Education, 85(4). https://doi.org/10.1002/jdd.12470

Hao, F., Tan, W., Jiang, L., Zhang, L., Zhao, X., Zou, Y., Hu, Y., Luo, X., Jiang, X., McIntyre, R. S., Tran, B., Sun, J., Zhang, Z., Ho, R., Ho, C., \& Tam, W. (2020). Do psychiatric patients experience more psychiatric symptoms during COVID-19 pandemic and lockdown? A case-control study with service and research implications for immunopsychiatry. Brain, Behavior, and Immunity, 87, 100-106. https://doi.org/10.1016/j.bbi.2020.04.069

Hasanagic, S. (2020). The dark shadow of a world crisis: a study on how organizations in Östergötland county manage, organize and plan for the effects of the Corona pandemic 2020. http://urn.kb.se/resolve?urn=urn:nbn:se:sh:diva-43584

Hidayu, F., \& Vasudevan, H. (2020). Covid-19 Pandemic During 2020 Malaysia Movement Control (MCO) - The Case of Residential College Students' Mental Health. International Journal of Social \& Scientific Research, 6(1), 1- 17.

Shafran, R., Sweeney, A., ... Bullmore, E. (2020). Multidisciplinary research priorities for the COVID-19 pandemic: a call for action for mental health science. In The Lancet Psychiatry (Vol. 7, Issue 6, pp. 547-560). Elsevier Ltd. https://doi.org/10.1016/S2215-0366(20)30168-1

Khairul, M., Noh, A., \& Zainon, S. (2021). A icQoL2021BukitTinggi AMER International Conference on Quality of Life Emotional Challenges across the Welfare provided among the Stranded University Students during Covid-19 Pandemic, (2020), 17-18. 
Moore, S. A., Faulkner, G., Rhodes, R. E., Brussoni, M., Chulak-Bozzer, T., Ferguson, L. J., Mitra, R., O'Reilly, N., Spence, J. C., Vanderloo, L. M., \& Tremblay, M. S. (2020). Impact of the COVID-19 virus outbreak on movement and play behaviours of Canadian children and youth: A national survey. International Journal of Behavioral Nutrition and Physical Activity, 17(1), 1-11. https://doi.org/10.1186//s12966020-00987-8

Odriozola-González, P., Planchuelo-Gómez, Á., Irurtia, M. J., \& de Luis-García, R. (2020). Psychological effects of the COVID-19 outbreak and lockdown among students and workers of a Spanish university. Psychiatry Research, 290, 113108. https://doi.org/10.1016/j.psychres.2020.113108

Omar, J., Friddy, A., Serun, A. T., B. Rayandran, H., Remash, J. R., Mohd Zuhurin, J. N., Adruce, M. N. S., \& Jayaveeran, Y. (2021). Psychological Impact on Parents of University Students During COVID19 Movement Control Order (MCO). Journal of Cognitive Sciences and Human Development, 7(1), 145-156. https://doi.org/10.33736/jcshd.2895.2021

Phelan, A. L., Katz, R., \& Gostin, L. 0. (2020). The Novel Coronavirus Originating in Wuhan, China: Challenges for Global Health Governance. In JAMA - Journal of the American Medical Association (Vol. 323, Issue 8, pp. 709-710). American Medical Association. https://doi.org/10.1001/jama.2020.1097 